\title{
SISTEMA DE CONFINAMENTO COMPOST BARN: INTERAÇÕES ENTRE ÍNDICES DE CONFORTO, CARACTERÍSTICAS FISIOLÓGICAS, ESCORE DE HIGIENE E CLAUDICAÇÃO
}

\author{
Vania Corrêa Mota \\ Ednilton Tavares de Andrade ${ }^{2}$ \\ Daniel Furtado Leite ${ }^{3}$
}

MOTA, V. C.; ANDRADE, E. T. de; LEITE, D. F. Sistema de confinamento Compost Barn: interações entre índices de conforto, características fisiológicas, escore de higiene e claudicação. Arquivos de Ciências Veterinárias e Zoologia da UNIPAR, Umuarama, v. 23, n. 1 cont., e2308, 2020.

RESUMO: O objetivo desse artigo foi avaliar o conforto térmico de bovinos leiteiros confinados em instalações Compost Barn com base em índices de conforto térmico, parâmetros fisiológicos, escore de higiene e claudicação. A pesquisa foi realizada, em uma propriedade do município de Três Corações no estado de Minas Gerais no período de verão e inverno de 2016. As variáveis microclimáticas e os escores de limpeza e de locomoção foram analisadas por meio da estatística descritiva. Os parâmetros fisiológicos foram submetidos a um delineamento experimental em blocos casualizados em parcela subdividida no tempo, por meio da análise de variância e teste de Scott-Knott. Pode-se concluir que não ocorreu estresse térmico nos animais na estação de verão e inverno. Os parâmetros fisiológicos se encontraram dentro dos limites de conforto animal. Existe um relacionamento maior entre a frequência respiratória, temperatura superficial e temperatura retal e os índices de conforto animal no verão, quando comparada com o inverno. Para a análise dos escores, as vacas apresentaram uma melhoria na limpeza e um número muito baixo de vacas com problemas de cascos.

PALAVRAS-CHAVE: Conforto animal. Estresse térmico. Fatores ambientais. Análise estatística.

\section{COMPOST BARN HOUSING SYSTEMS: INTERACTIONS AMONG COMFORT INDEXES, PHYSIOLOGICAL CHARACTERISTICS, HYGIENE SCORE, AND CLAUDICATION}

\begin{abstract}
The purpose of this article is to evaluate the thermal comfort of dairy cattle confined in compost barn facilities based on thermal comfort indexes, physiological parameters, hygiene score, and claudication. The research was carried out in a property in the city of Três Corações in the state of Minas Gerais during the summer and winter of 2016. The microclimatic variables and the cleaning and locomotion scores were analyzed through a descriptive statistics analysis. The physiological parameters were submitted to an experimental design in randomized blocks in a subdivided plot, using analysis of variance and Scott-Knott's test. It can be concluded that no thermal stress occurred on the animals during the summer and winter seasons. There is a greater relationship between respiratory rate, surface and rectal temperature, and the animal comfort indexes in summer compared to winter. For the analysis of the scores, the cattle showed an improvement in cleaning and a very low number of cows presented hoof problems.
\end{abstract}

KEYWORDS: Animal comfort. Thermal stress. Environmental factors. Statistical analysis.

\section{SISTEMA DE CONFINAMIENTO COMPOST BARN: INTERACCIONES ENTRE ÍNDICES DE CONFORT, CARACTERÍSTICAS FISIOLÓGICAS, PUNTUACIÓN DE HIGIENE Y CLAUDICACIÓN}

RESUMEN: El objetivo de este artículo es evaluar el confort térmico de bovinos lecheros confinados en instalaciones Compost Barn con base en índices de confort térmico, parámetros fisiológicos, puntuación de higiene y claudicación. La investigación se realizó en una propiedad del municipio de Tres Corações en el estado de Minas Gerais, en el período de verano e invierno de 2016. Las variables microclimáticas y los escores de limpieza y de locomoción fueron analizados por medio de estadística descriptiva. Los parámetros fisiológicos fueron sometidos a un delineamiento experimental en bloques casualizados en parcela subdividida en el tiempo, por medio del análisis de varianza y prueba de Scott-Knott. Se puede concluir que no ocurrió estrés térmico en los animales en la estación de verano e invierno. Los parámetros fisiológicos se encontraron dentro de los límites de confort animal. Hay una relación mayor entre la frecuencia respiratoria, la temperatura superficial y la temperatura rectal y los índices de confort animal en verano, en comparación con el invierno. Para el análisis de los escores, las vacas presentaron mejora en la limpieza y un número muy bajo de vacas con problemas de cascos.

PALABRAS CLAVE: Confort animal. Estrés térmico. Factores ambientales. Análisis estadístico.

\footnotetext{
DOI: 10.25110 /arqvet.v23i1cont.2020.6969

${ }^{1}$ Professora Adjunta do Departamento Acadêmico de Matemática e Estatística - DAME, Universidade Federal de Rondônia, Campus Ji-Paraná. E-mail: vaniamota33@gmail.com

${ }^{2}$ Professor Associado IV da Universidade Federal de Lavras, MG. Coordenador do Programa de Pós-graduação em Engenharia Agrícola da UFLA, MG. ${ }^{3}$ Professor Adjunto do Departamento de Engenharia (Núcleo de Eletricidade e Automação) da Universidade Federal de Lavras (DEG-UFLA), MG.
} 


\section{Introdução}

Um dos desafios para a produtividade pecuária diz respeito ao monitoramento do estado de bem estar dos animais e controle do estresse térmico. $\mathrm{O}$ estresse térmico é capaz de provocar grandes prejuízos no sistema de produção, como queda na produção de leite e nos índices reprodutivos, sendo que o método de quantificar ou medir a sensação de calor se dá por meio dos fatores ambientais, como: a temperatura do ambiente, a umidade relativa do ar, a radiação solar, a velocidade do vento, e por fatores individuais, como o metabolismo e o tipo de pelame dos animais (FERREIRA, 2015; SILVA, 2016).

O estudo da ambiência e das instalações para bovinos leiteiros, e o conhecimento dos efeitos dos fatores ambientais e fisiológicos, devem ser analisados em conjunto, pois existe uma inter-relação entre esses fatores que influenciam no desempenho e na produção dos animais (BERTONCELLI et al., 2013; PINHEIRO et al., 2015). Alguns dos maiores problemas enfrentados pelos produtores brasileiros são o micro clima das instalações e as altas temperaturas encontradas no país. Por exemplo, as raças com maior desempenho produtivo, como o gado Jersey e o gado Holandês, que são raças de origem europeia e, portanto, são mais adaptados ou apropriados ao clima temperado (MOTA, 2018).

A temperatura ambiente pode influenciar a produtividade das vacas leiteiras, por alterar a troca de calor com o ambiente e a taxa de ingestão de alimento e, simultaneamente, afetar ou mudar as exigências em nutrientes dos animais.

Devido à grande variação de microclimas e a grande diversidade de raças produtoras de leite, o estudo da influência dos fatores ambientais em torno das vacas leiteiras, tem se tornado um dos aspectos mais pesquisados, no intuito de melhorar a produtividade desse setor no Brasil (PINHEIRO et al., 2015).

Particularmente, as variáveis fisiológicas (temperatura retal, temperatura superficial e frequência respiratória), variáveis de bem estar animal (escore de higiene e claudicação) e os fatores ambientais que influenciam na adaptação de bovinos leiteiros ao ambiente tropical, a serem considerados neste trabalho, são tema de pesquisa de diversos autores, tais como Avila et al. (2013), Black et al. (2014), Zero e Melo (2015) Pinheiro et al. (2015), Araujo et al. (2016), Eckelkamp et al. (2016), Mota et al. 2018, Costa et al. (2018), entre outros.

O sistema de confinamento compost barn é um sistema alternativo ao conhecido sistema Loose Housing, onde os animais ficam soltos e podem caminhar livremente dentro do galpão (MOTA et al., 2017; MOTA, 2018), têm como principal característica a área de descanso dos animais (cama), que consiste em uma mistura de fonte de carbono e o material orgânico rico em nitrogênio originário das fezes e da urina dos animais (BLACK et al., 2014; MOTA, 2018).

Diante do exposto, o objetivo desse artigo foi avaliar o conforto térmico de bovinos leiteiros confinados em instalações compost barn com base em índices de conforto térmico, parâmetros fisiológicos, escore de higiene e claudicação.

\section{Material e Métodos}

A pesquisa foi realizada em um confinamento para bovinos leiteiros no modelo compost barn, em uma propriedade rural do município de Três Corações no estado de Minas Gerais. Segundo a classificação internacional de Köppen, o clima da região é do tipo CWA, caracterizado por duas estações bem definidas: uma seca e de menores temperaturas, que se estende de maio a setembro, e outra úmida e de temperaturas mais elevadas, de outubro a abril. A temperatura média anual é de $20,2{ }^{\circ} \mathrm{C}$ e a precipitação anual é de 1,401 mm (MOTA, 2018; MOTA, TAVARES; LEITE, 2019; MOTA et al., 2019).

A temperatura média do ar e a umidade relativa externa do galpão durante os dias de coleta dos dados foram obtidos por meio da estação meteorológica portátil modelo No. ITWH - 1080 da Instrutemp (precisão de $\pm 1{ }^{\circ} \mathrm{C} ; 5 \%$ UR; $\mathrm{e} \pm 1 \mathrm{~m} / \mathrm{s}$ ) com sensores apropriados para coletar e armazenar os dados.

O galpão, em sistema de confinamento modelo compost barn (CB) (MOTA et al. 2017, MOTA, 2018), com orientação Noroeste/Sudoeste, possui 18,70 metros de largura por 50 metros de comprimento, pé direito de quatro metros, e cumeeira de seis metros. Sendo $13 \mathrm{~m}$ x $50 \mathrm{~m}$ destinados à área de descanso com cama, divididos em três lotes (alta produção de leite, média produção de leite e baixa produção de leite), separados por meio de cerca elétrica, sendo esta área utilizada para análise (Figura 1).

O galpão possui um corredor de alimentação medindo $3 \mathrm{~m}$ x $50 \mathrm{~m}$ com um comedouro (cocho de volumoso) em toda a extensão do galpão. E outro corredor medindo 2 $\mathrm{m} \times 50 \mathrm{~m}$, com quatro bebedouros medindo $0,50 \mathrm{~m} \times 2 \mathrm{~m}$ (fundo formato trapézio) com capacidade para 300 litros de água. Possui três cochos de mineral e cinco ventiladores centralizados a uma altura de 3,20 metros na área de descanso (com 6 hélices) da marca Roster que proporciona uma vazão de $48,000 \mathrm{~m}^{3}$ de ar por hora cada um.

Figura 1: Panta baixa do galpão compost barn.

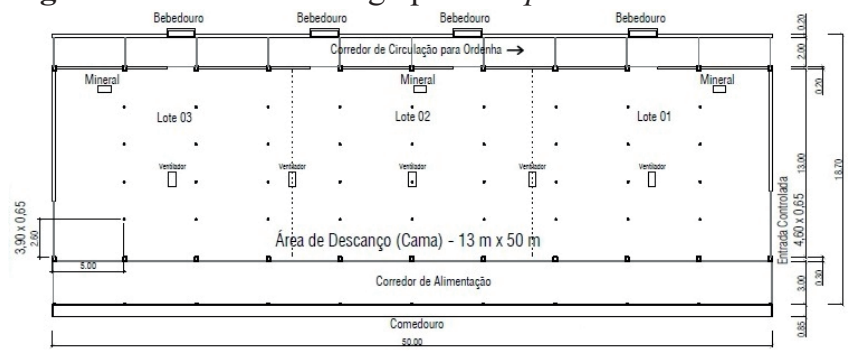

- Descrição - coleta de dados

A pesquisa foi conduzida: durante o Verão de 2016 - Tratamento VER e Inverno de 2016 - Tratamento INV. Os registros de dados foram realizados em janeiro de 2016, nos dias 17 no P1; 24 no P2; 31 no P3 e no mês de julho, nos dias 17 no P4; 24 no P5; 31 no P6. As coletas foram divididas em duas etapas:

$1^{\text {a }}$ etapa: Foram coletadas 36 amostras, para as variáveis, temperatura do ar (TA), umidade relativa (UR), velocidade do ar $(\mathrm{v})$, temperatura do ponto de orvalho $\left(\mathrm{T}_{\mathrm{po}}\right)$ e temperatura do globo negro $\left(\mathrm{T}_{\mathrm{gn}}\right)$, em uma malha regular com 36 pontos georeferenciados, divididos em 12 pontos por lote, distribuídos uniformemente ao longo do galpão com 
espaçamento de 2,6 $\mathrm{m}$ por cinco metros. Considerou-se para análise os valores médios das variáveis.

As medidas foram realizadas a 1,8 $\mathrm{m}$ do piso (cama), em cada posição da malha regular de pontos. As coletas de dados foram feitas no sistema de confinamento no modelo compost barn, duas vezes ao dia, com inicio nos horários das 9:00 e 15:00 h, com os ventiladores ligados (Figura 1).

O equipamento utilizado para o registro de dados foi o sensor portátil da marca Kestrel ${ }^{\circledR}$, modelo 3000, com faixa de registro de velocidade do ar e umidade com precisão de $\pm 3 \%$ da leitura; temperatura (precisão de $\pm 1{ }^{\circ} \mathrm{C}$ ), ponto de orvalho (precisão de $\pm 3{ }^{\circ} \mathrm{C}$ ) e temperatura do bulbo úmido (precisão de $\pm 2{ }^{\circ} \mathrm{C}$ ). A temperatura do globo negro foi registrada por meio de um medidor de temperatura digital, sensor externo (Termopar tipo K) inserido no centro do globo negro (esfera oca com $7 \mathrm{~cm}$ de diâmetro e pintada de preto fosco), que foram coletados manualmente.

A partir dos dados medidos nos horários prédeterminados foram obtidos os índices de temperatura e umidade (ITU) (AVILA et al., 2013); o Índice de temperatura de globo negro e umidade (ITGU) (MOURA et al., 2010) e a Índice de Carga Térmica Radiante (CTR) (AVILA et al., 2013).

$2^{\text {a }}$ etapa: Foram coletados os parâmetros fisiológicos, frequência respiratória (FR), temperatura da superfície do animal (TS) e temperatura retal (TR) duas vezes ao dia escolhendo 15 animais de acordo com uma amostragem aleatória estratificada proporcional em cada divisão da instalação (lotes), determinada pela seguinte Eq. 1 (FERREIRA, 2005):

$n_{h}=\frac{N_{h}}{N} \cdot n$

em que $\mathrm{n}_{h}$ determina a amostra do estrato; $\mathrm{N}_{\mathrm{h}}$ é o tamanho do estrato (divisão da instalação - lote) $n$ é o tamanho da amostra (15 animais) e $N$ é o tamanho da população (total de vacas no galpão).

A FR foi mensurada pela contagem dos movimentos do flanco, durante 20 segundos e o valor foi multiplicado por três para se obter a frequência dos movimentos respiratórios por minuto (AVILA et al., 2013). Para aferição da TR, utilizouse um termômetro digital, inserido aproximadamente $5 \mathrm{~cm}$ no reto do animal. A TS foi obtida pela média da temperatura corporal coletada com um termômetro de infravermelho em quatro pontos do animal, fronte, cernelha, virilha e jarrete (Figura 2).

Figura 2: Detalhe da coleta da temperatura corporal com termômetro infravermelho.

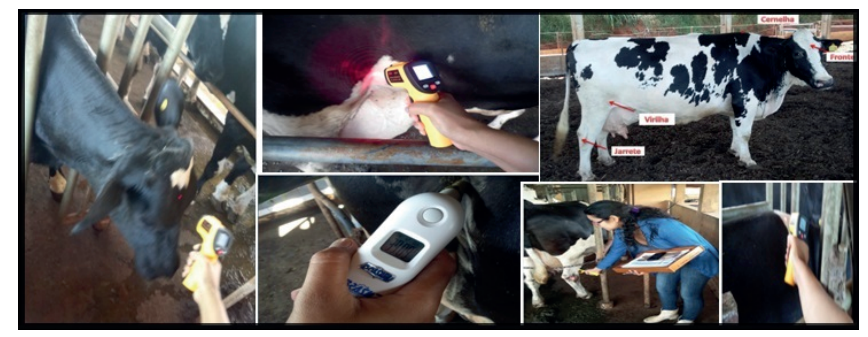

Nessa etapa também foram avaliados os escores de limpeza e de locomoção dos animais (COOK; REINEMANN, 2007). A claudicação foi avaliada observando as vacas andando, por meio do sistema de pontuação de locomoção de Sprecher, Hostetler e Kaneene, (1997) onde 1 é igual a normal, 2 é igual a levemente coxo, 3 é igual a moderadamente coxo, 4 é igual a coxo e 5 é igual a severamente coxo. A observação da locomoção foi realizada estimulando o animal a se mover e com isso avaliar pernas e partes posteriores. Vacas com escore de locomoção $\geq 3$ foram classificadas como clinicamente manca (ECKELKAMP et al., 2016). A higiene foi avaliada usando um sistema variando de 1 a 4 , onde 1 significa limpo e 4 significa imundo e sujo, analisando a limpeza do úbere e pernas traseiras (COOK; REINEMANN, 2007).

As variáveis microclimáticas coletadas no verão e no inverno foram analisadas por meio dos procedimentos da análise de estatística descritiva, sendo determinado a média, desvio padrão, coeficiente de variação e valores de máximo e de mínimo (BANZATTO; KRONKA, 2015). Os dados referentes aos parâmetros fisiológicos inicialmente foram submetidos à análise de resíduos, considerou-se um delineamento experimental em blocos casualizados em parcela subdividida no tempo com dois tratamentos (estação - VER e INV), três tempos de coletas (dias 17, 24 e 31) e quinze repetições, totalizando 90 observações para cada variável.

Os dados foram analisados pelo software SISVAR 5.1 (FERREIRA, 2011) por meio da análise de variância, e teste de Scott-Knott para a comparação de médias, adotando um nível de significância de 5\%. Posteriormente aplicouse aos dados a análise de correlação de Pearson entre as variáveis analisadas, parâmetros fisiológicos dos animais (FR, TS e TR) e os índices de conforto animal CTR, ITU e ITGU. Para os escores de limpeza e de locomoção aplicou-se uma análise descritiva dos dados.

\section{Resultados e Discussão}

Os valores médios de temperatura externa no verão e inverno de 2016 foram de $26,5^{\circ} \mathrm{C}$ e $21,2{ }^{\circ} \mathrm{C}$ respectivamente e os valores médios de umidade foram $72 \%$ no verão e $58 \%$ no inverno.

$\mathrm{Na}$ Tabela 1 estão apresentados os resultados da estatística descritiva das variáveis microclimáticas. A variabilidade dos dados foi baixa para a temperatura do ar e para os índices CTR, ITGU e ITU, com valores de coeficientes de variação menor que 4\% às 15:00 h.

Verificou-se que a temperatura do ar aumentou no período da tarde, tanto no verão quanto no inverno, porém os valores permaneceram dentro do limite de conforto animal no inverno, que para bovinos em lactação é recomendável estar abaixo de $24{ }^{\circ} \mathrm{C}$ (AVILA et al. 2013), apenas no turno da tarde do verão os animais não estiveram dentro desse limite de conforto. A média da umidade relativa do ar (UR) no verão foi de $63.4 \%$ e no inverno de $58.8 \%$, apresentando valores abaixo do valor considerado limite (70\%) para vacas lactantes em clima quente (PINHEIRO et al., 2015). Esses valores de TA e UR corroboram com os encontrados por Araujo et al. (2016), que pesquisaram essas variáveis pelo turno da manhã, das $09 \mathrm{~h} 00 \mathrm{~min}$ às $10 \mathrm{~h} 00 \mathrm{~min}$ e pelo turno da tarde, das $15 \mathrm{~h} 00 \mathrm{~min}$ às $16 \mathrm{~h} 00 \mathrm{~min}$. e encontraram valores médios de $25.59{ }^{\circ} \mathrm{C}$ e $57.69 \%$ para vacas mestiças (Holandesas x Gir) em lactação durante os anos de 2010 a 2013, em Bom Jesus-PI. 
Tabela 1: Estatística das varáveis microclimáticas do estábulo em sistema modelo compost barn estudadas nas estações de verão e inverno de 2016.

\begin{tabular}{ccccccccc}
\hline \multicolumn{9}{c}{ Verão - 9 horas } \\
\hline Estatísticas & T. A. & CTR & ITGU & ITU & T. A. & CTR & ITGU & ITU \\
\hline $\bar{x}$ & 24,15 & 468,6 & 80,7 & 72,7 & 18,59 & 485,4 & 73,9 & 63,8 \\
S & 0,21 & 32,9 & 1,9 & 0,5 & 0,37 & 57,8 & 2,5 & 0,6 \\
C. V. (\%) & 0,90 & 7,0 & 2,4 & 0,7 & 2,01 & 11,9 & 3,3 & 0,9 \\
Mín. & 23,73 & 441,4 & 79,2 & 71,7 & 17,86 & 404,7 & 70,8 & 61,9 \\
Máx. & 24,6 & 568,0 & 85,0 & 73,7 & 19,4 & 614,0 & 79,1 & 64,6 \\
\hline \multicolumn{9}{c}{ Verão - 15 horas } \\
\hline Estatísticas & T. A. & CTR & ITGU & ITU & T. A. & CTR & ITGU & ITU \\
\hline $\bar{x}$ & 27,31 & 476,8 & 82,8 & 74,5 & 23,23 & 451,6 & 75,4 & 65,5 \\
S & 0,82 & 18,3 & 1,0 & 1,5 & 0,22 & 17,4 & 0,7 & 1,0 \\
C. V. (\%) & 3,93 & 3,8 & 1,3 & 1,9 & 0,95 & 3,8 & 1,0 & 1,5 \\
Mín. & 24,93 & 448,8 & 81,3 & 70,5 & 22,9 & 365,6 & 73,2 & 63,6 \\
Máx. & 30,47 & 576,7 & 85,2 & 79,2 & 23,7 & 475,9 & 76,9 & 67,8
\end{tabular}

$\overline{\bar{x}}=$ Média, C. V. = Coeficiente de Variação, $\mathrm{S}=$ Desvio padrão, Mín. = Mínimo, Máx. $=$ Máximo, T. A. $\left({ }^{\circ} \mathrm{C}\right)=$ Temperatura do ar, CTR $=$ Índice de Carga Térmica Radiante, ITGU = Índice de temperatura de globo negro e umidade, ITU = Índices de temperatura e umidade.

Os valores dos índices de conforto animal acompanharam os valores de TA e apresentaram aumentos no período da tarde para as duas estações analisadas. Adotouse a tabela de ITU para bovinos leiteiros de alta produção proposta por Ferreira (2015) em que o ITU abaixo de 68 indica sem estresse; de 69 a 71 indica um leve estresse; de 72 a 79 indica um estresse ameno; de 79 a 89 indica um estresse moderado; e de 90 a 98 indica estresse grave). Dessa forma, observou-se que no inverno o ITU apresentou, em média, um ambiente sem estresse e de conforto para os animais. No verão este índice foi maior à tarde estando dentro da faixa de estresse ameno.

No verão, os resultados de máximo e mínimo do ITGU indicam que os animais encontram-se em situação de perigo podendo acarretar baixo rendimento, na produção de leite (MOURA et al., 2010), isso foi verificado às 9:00 horas e às 15:00 horas. Já no inverno, o valor médio e o valor de mínimo às 9:00 horas de ITGU estão abaixo do intervalo de alerta, mas o valor de máximo encontra-se no intervalo de situação de perigo para os animais (AVILA et al., 2013). Valores semelhantes foram encontrados em Araujo et al. (2016) que recomendam em tais situações a necessidade de intervenção humana, sendo esta por meio de instalações, sistemas de climatização (ventiladores, nebulizadores, entre outros) que promova um ambiente de conforto para os animais.

A ventilação do ambiente, mesmo não reduzindo a temperatura do ar, promove aumento do processo convectivo de troca e, se estiver dentro das recomendações, melhora a sensação térmica do animal. A renovação do ar beneficia a secagem da cama e a eliminação dos gases excretados (SILVA, 2016), possibilitando, dentro de certos limites, controlar a temperatura do ar e a umidade relativa do ambiente. Em sistemas produtivos para bovinos leiteiros, as instalações têm a função de abrigar os animais e criar um microclima com fatores climáticos amenizados (MOURA et al., 2010).

Segundo Leso et al. (2017) em climas mais quentes, as características dos materiais normalmente usados na construção dos telhados podem representar um desafio para manter a temperatura interna adequada durante os meses de verão. Os autores ressaltam que uma cobertura verde, com vegetação, pode ter um papel importante no desenvolvimento futuro de sistemas de criação intensivo de vacas leiteiras, e apesar de existir algumas questões relativas à sua utilização, esse tipo de cobertura tem o potencial para reduzir os custos de produção, melhorar o bem-estar animal e reduzir o impacto do calor na produção leiteira. Verificaram, em seu estudo, que o uso da cobertura verde melhora o desempenho térmico do ambiente e tem o potencial de reduzir a energia para fins de refrigeração e acrescentam que mais pesquisas são necessárias para desenvolver soluções construtivas sustentáveis e adequadas para a pecuária.

$\mathrm{O}$ índice CTR, tem seus resultados influenciados pelos materiais utilizados na construção da instalação, bem como os efeitos dos ventos e da temperatura (SILVA, 2016). Nesse estudo, no verão os valores médios de CTR, como descritos na Tabela 1, foram registrados nos horários das 9 e $15 \mathrm{~h}$. Semelhante ao que ocorreu as demais variáveis, houve um aumento da CTR entre as 9 e $15 \mathrm{~h}$, que passou de 468.6 $\mathrm{W} \mathrm{m}^{-2}$ as $9 \mathrm{~h}$, para $476.8 \mathrm{~W} \mathrm{~m}^{-2}$ às $15 \mathrm{~h}$ com os ventiladores ligados. Esses valores se assemelham aos encontrados por Kawabata, Castro e Júnior, (2005) que cita valores médios de CTR no horário das 8 h que variaram de 454.84 a 484.30 $\mathrm{W} \mathrm{m}^{-2}$, enquanto no inverno a CTR no período da manhã apresentou valores médios de $485.4 \mathrm{~W} \mathrm{~m}^{-2}$, esses valores foram maiores que os encontrados à tarde, de modo geral são desejáveis os menores valores possíveis de CTR.

Com base na análise de resíduos, verificou-se que, a análise de variância realizada é aceitável, isso significa que as pressuposições sobre os erros foram satisfeitas, isto é, os erros são variáveis aleatórias independentes, a variância é constante e a distribuição dos erros é normal ou aproximadamente normal (BANZATTO; KRONKA, 2015). De modo geral, o experimento apresentou uma boa precisão, com coeficientes de variação abaixo de $11.9 \%$.

Observou-se com os resultados da análise de variância que a interação entre os tratamentos (estação VER 
e INV) versus o tempo (dias de coleta) para TS e a FR no período da manhã e da tarde foi significativo, dessa forma procedeu-se com o desdobramento das duas estações dentro dos três dias de coleta. Já para a TR no período da manhã o teste $\mathrm{F}$ da análise de variância não foi significativo, i. e., não houve diferença estatística entre os valores médios de TR para as duas estações (Tabela 2), e para essa variável no período da tarde a interação foi significativa e aplicou-se o desdobramento.

Tabela 2: Valores médios de temperatura retal, temperatura superficial e frequência respiratória do período da manhã de vacas Holandesas em lactação, alojadas em sistema de confinamento compost barn.

\begin{tabular}{cccc}
\hline & \multicolumn{3}{c}{ Temperatura Retal $\left({ }^{\circ} \mathrm{C}\right)$} \\
\hline Estação & Coleta - dia 17 & Coleta - dia 24 & Coleta - dia 31 \\
\hline Verão & 38,30 a A & 37,95 a A & 38,40 a A \\
Inverno & 38,31 a A & 38,10 a A & 38,09 a A \\
\hline Verão & Temperatura Superficial $\left({ }^{\circ} \mathrm{C}\right)$ & 30,69 a A \\
Inverno & 29,43 a A & 26,65 a A & 27,94 b B \\
\hline Verão & 25,34 b B & 26,84 b A & 42,80 a A \\
\hline Inverno & 50,60 a A & Frequência Respiratória (mov.min.-1) & $39,8 \mathrm{~b} \mathrm{~B}$
\end{tabular}

a,b - em cada estação, médias de cada dia de coleta seguidas de mesma letra minúscula, na linha, não diferem (Scott-Knott 5\%).

A,B - em cada dia de coleta, médias da estação seguidas de mesma letra maiúscula, na coluna, não diferem (Scott-Knott 5\%).

O valor médio de TR no verão foi de $38,15{ }^{\circ} \mathrm{C}$ e no inverno de $38,27^{\circ} \mathrm{C}$, esses valores estão de acordo com valores normais de temperatura retal para bovinos que está em torno de $38.3^{\circ} \mathrm{C}$ (ARAUJO et al., 2016).

A temperatura superficial $\left({ }^{\circ} \mathrm{C}\right)$ dos animais foi maior no verão com valores médios de $28.92{ }^{\circ} \mathrm{C}$ do que no inverno no período da manhã (Tabela 2). Verificaram-se para o período da manhã e da tarde diferença significativa entre as estações, verão e inverno. No período da tarde no dia de coleta 17 não foi verificado diferença entre as estações, no entanto, nos dias 24 e 31 observou-se tal diferença, de acordo com o teste de Scott-Knott (5\%), com valores mais elevados da temperatura superficial das vacas no verão (Tabela 3 ). Os valores de temperatura superficial não indicaram sofrimento por estresse térmico no ambiente analisado, pois o resultado se encontra entre 31.6 a $34.7^{\circ} \mathrm{C}$ (ZERO; MELLO, 2015).

A frequência respiratória faz referência ao número de respirações ou ciclos por minuto e é usada como variável fisiológica para analisar a termorregulação animal (PILATTI; VIEIRA, 2017). A FR tanto no horário da manhã quanto no horário da tarde, apresentou maiores valores no verão quando comparados com valores do inverno. Apresentou valor médio de FR no verão de 45,6 e 49,5 mov. min. ${ }^{-1}$ de manhã e tarde respectivamente, e no inverno verificou valor médio de 41,5 mov. min..$^{-1}$ no período da manhã e 45,07 mov. min. ${ }^{-1}$ à tarde.

Tabela 3: Valores médios de temperatura retal, temperatura superficial e frequência respiratória do período da tarde de vacas Holandesas em lactação, alojadas em sistema de confinamento compost barn.

\begin{tabular}{cccc}
\hline & & Temperatura Retal $\left({ }^{\circ} \mathrm{C}\right)$ & Coleta - dia 31 \\
\hline Estação & Coleta - dia 17 & Coleta - dia 24 & 39,09 a A \\
\hline Verão & 38,56 a A & 39,59 a A & 38,54 a B \\
Inverno & 37,66 a B & 38,04 a B & 34,72 a A \\
\hline Verão & & Temperatura Superficial $\left({ }^{\circ} \mathrm{C}\right)$ & 31,49 b B \\
\hline Inverno & 30,85 a A & 33,06 a A & 58,20 a A \\
\hline Verão & 30,86 b A & 31,12 b B & 46,40 b B \\
\hline Inverno & 46,60 a A & Frequência Respiratória (mov.min.-1) & 43,60 a A \\
\hline
\end{tabular}

a,b - em cada estação, médias de cada dia de coleta seguidas de mesma letra minúscula, na linha, não diferem (Scott-Knott 5\%).

A,B - em cada dia de coleta, médias da estação seguidas de mesma letra maiúscula, na coluna, não diferem (Scott-Knott 5\%).

Valores semelhantes foram observados em Araujo et al. (2016) que verificaram valores médios de frequência respiratória no verão e no inverno de 43,22 mov. min. ${ }^{-1}$ ao trabalharem com vacas mestiças. Essa diferença entre as estações pode ser atribuída à adaptação dos animais a temperatura ambiente que normalmente no verão encontrase aumentada, devido à maior influência da radiação solar
(PINHEIRO et al., 2015).

Os valores de FR ultrapassando os 120 mov. min. ${ }^{-1}$ indicam que o animal está sofrendo com a carga excessiva de calor e, acima de 160 mov. min. $^{-1}$, medidas de emergência devem ser tomadas, a fim de amenizar o estresse térmico (ARAUJO et al., 2016). Dessa forma, percebe-se que durante os dias de coletas deste trabalho, os animais nas estações de 
verão e inverno estiveram dentro dos níveis de conforto.

Os parâmetros fisiológicos de temperatura retal (TR), frequência respiratória (FR), temperatura superficial da pele (TS) sofrem influência do turno do dia, uma vez que à tarde a temperatura do ar é geralmente mais elevada que durante a manhã, promovendo uma elevação dessas variáveis fisiológicas (SOUZA et al., 2012). Temperaturas elevadas comprometem negativamente a temperatura retal $\mathrm{e} a$ frequência respiratória (KAWABATA; CASTRO; JÚNIOR, 2005).

Com o interesse de conhecer o tipo de relacionamento existente entre os parâmetros fisiológicos dos animais (FR, TS e TR) e os índices de conforto animal CTR, ITU e ITGU nas duas estações, calcularam-se os coeficientes de correlação de Pearson que estão apresentados na tabela 4.

Tabela 4: Resultados dos coeficientes de correlação de Pearson entre os parâmetros fisiológicos e os índices de conforto de vacas Holandesas em lactação, alojadas em sistema de confinamento compost barn.

\begin{tabular}{|c|c|c|c|c|c|c|c|}
\hline \multicolumn{4}{|c|}{ VERÃO } & & \multicolumn{3}{|c|}{ INVERNO } \\
\hline & CTR & ITGU & ITU & & CTR & ITGU & ITU \\
\hline FR & 0,16 & 0,45 & 0,40 & FR & 0,02 & $-0,11$ & $-0,11$ \\
\hline TR & 0,27 & $0, .01$ & $-0,06$ & $\mathrm{TR}$ & 0,06 & $-0,21$ & 0,25 \\
\hline TS & $-0,27$ & $-0,25$ & $-0,10$ & $\mathrm{TS}$ & 0,10 & $-0,12$ & $-0,34$ \\
\hline
\end{tabular}

A configuração nos resultados sugere a existência de um relacionamento maior entre a FR, TS e TR e os índices CTR, ITU e ITGU no verão. A frequência respiratória foi à variável fisiológica que apresentou uma correlação maior com os índices de conforto animal. No verão a correlação da FR foi positiva com o ITGU e ITU de 0,45 e 0,40 respectivamente. Já no inverno essa variável não sofreu alteração e a correlação foi fraca quando relacionada com os índices, verificando correlações negativas entre o ITGU e ITU. Tal fato pode ser justificado levando em conta que os resultados da FR das vacas confinadas no compost bar estavam dentro da faixa de conforto, e o ambiente apresentava conforto para os animais, não havendo a necessidade de uma alteração da frequência respiratória, que de acordo com Zero e Mello (2015) atua como um mecanismo de adaptação dos animais ao estresse térmico.

A temperatura retal também apresentou uma fraca correlação com os índices, sendo que no verão apresentou uma correlação positiva com a CTR e ITGU e negativa com o índice ITU. No inverno também se verificou correlações fracas, porém, apenas com valores negativos para a ITGU. Esses resultados corroboram com os encontrados em Avila et al. (2013), que verificaram correlação negativa, e não significativa $(\mathrm{P}>0,05)$ em relação aos índices bioclimáticas ITU, ITGU e CTR. Relatam ainda que tal fato deva ter ocorrido porque a TR não acompanhou as variações de aumento dos índices ao longo o dia.

A temperatura superficial da pele dos animais, também apresentou uma fraca correlação com os índices, sendo apenas correlacionada positivamente no inverno com a CTR, com os demais índices para as duas estações o relacionamento foi negativo, indicando que nesse estudo, os valores dos índices de conforto animal não influenciaram nos valores de TS.

Deve-se ressaltar que nos horários estudados, o galpão de compost barn apresentou, de modo geral, condições de conforto aos animais, isso de alguma forma pode ter influenciado nos resultados das correlações, indicando que o clima ameno não afetou os parâmetros fisiológicos. Salienta-se que a técnica foi adequada e trouxe informações úteis, mostrando que os valores da temperatura, umidade e velocidade do ar do ambiente estando dentro dos desejáveis para o bem estar animal, exige pouca variação nos parâmetros fisiológicos dos animais, i. e., os animais com temperatura ambiente controlada, por exemplo, podem diminuir o ritmo da frequência respiratória para perder calor, que nesse caso é considerado uma estratégia energética, que torna a vida desses animais mais confortável (PINHEIRO et al., 2015).

Para os aspectos de higiene e claudicação, verificouse que $69,3 \%$ e $75,4 \%$ dos animais apresentam escore 1 de higiene para o verão e inverno respectivamente e $61,8 \%$ de escore de claudicação 1 para o verão, e no inverno $72,2 \%$ das vacas apresentaram escore 1, dessa forma, nesse estudo o sistema compost barn proporciona condições de conforto para que as vacas leiteiras expressem um elevado nível de bem-estar animal (Figura 3).

Figura 3: Resumo dos escores de claudicação (a) e higiene (b).

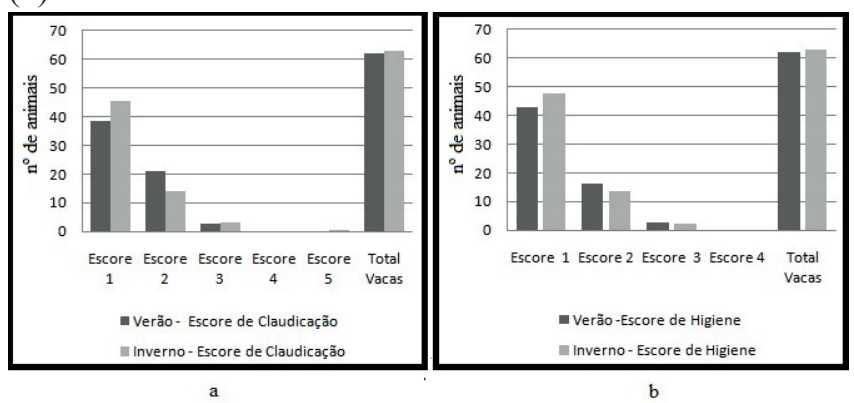

O escore um (1) de higiene indica que as vacas estão limpas, aparentemente com os úberes e a parte traseira sem sujeira, e o escore um (1) de claudicação sugere um rebanho com postura normal, passos firmes e distribuição uniforme do peso e apoio. Animais limpos fornecem informações sobre a limpeza do ambiente, que nesse sistema de confinamento é a área de descanso, onde estão as vacas. Mostram que o manejo do material de cama está sendo eficiente. Esses resultados vão ao encontro de resultados de Black et al. (2013) que ao estudar o conforto de vacas em lactação confinadas em sistema Compost Barn verificaram que a área de descanso desse sistema proporciona melhoria na higiene dos animais se bem manejadas. Os autores relatam que a maior frequência e a profundidade do revolvimento da cama, aumentam a sua temperatura e diminui a sua umidade, e acrescentam que profundidades de revolvimento maiores que $0,203 \mathrm{~m}$ 
apresentam melhores resultados.

Muitos fatores influenciam a claudicação e a prevalência de lesões em bovinos leiteiros como, a genética dos animais, o tipo de cama, entre outros (COSTA et al., 2018). No caso do free stall, verifica-se as dimensões das baias e se utiliza areia ou borracha, no caso do compost barn, e observado o tipo de material de cama (serragem, palhada de milho, etc.), fatores estes que podem ser controlados.

Pode se observar que o escore três de higiene ficou abaixo de $10 \%$, o que representa vacas limpas para os dois períodos estudados. Já o escore de claudicação apresentou $33,9 \%$ de animais com escore dois no verão e $22,3 \%$ no inverno, com uma redução com os passar dos meses de animais com postura arqueada em estado de locomoção com ligeira alteração dos passos. Nenhum animal com escore três nas duas estações foi observado, mas apresentou apenas um animal no inverno com escore cinco. $\mathrm{O}$ animal apresentava incapacidade de sustentação do peso dos membros lesionados e recusa para se locomover-se. De modo geral, os resultados indicam um número muito baixo de animais com problemas de cascos, com pequeno aumento no inverno de animais com postura arqueada. Esse fato ocorreu, segundo o proprietário, devido à falta de mão de obra especializada pra realizar o casqueamento dos animais, haja vista a troca de funcionários nesse período.

Nesse sentido, vale ressaltar a importância de realizar o casqueamento das vacas de forma periódica, pois as lesões nos cascos diminuem o consumo de alimentos e os animais com dificuldade de se locomover procuram menos o cocho e, consequentemente ocorrem perdas na produção de leite. De acordo com Bond et al. (2012) o animal afetado pela claudicação distribui o peso corporal de maneira desigual entre os quatro membros, levando a alterações na locomoção.

Recomenda-se realizar avaliações de escore de claudicação e higiene nos animais periodicamente, para avaliar o grau de injurias e limpeza dos animais confinados e com isso verificar o conforto dos animais na área de descanso (cama), ou seja, conferir se existe ou não a necessidade de adicionar mais material de cama (como a serragem), ou se a mesma precisa ser trocada. As fazendas onde os casos de claudicação são identificados e gerenciados de forma eficaz, ou seja, os animais tratados e cuidados são menos propensos a ter desempenho reprodutivo reduzido devido à claudicação, do que as fazendas onde a claudicação é insuficientemente gerenciada (SOMERS et al., 2015).

Em resumo, para a análise dos escores de higiene e claudicação, com o passar dos meses, as vacas em lactação alojadas no sistema de confinamento no modelo compost barn apresentaram uma melhoria na limpeza e um número muito baixo de vacas com problemas de cascos, sendo as primeiras coletas realizadas no verão de 2016, e as demais coletas ocorridas no inverno de 2016. Vale ressaltar que esta é uma análise pontual, realizada no sul de Minas Gerais, e que necessitam de mais pesquisas e amostras de outras fazendas que adotaram o modelo compost barn na região e no estado, portanto, não é representativa de todas as propriedades leiteiras dentro do estado de Minas Gerais - Brasil.

Em síntese, pode-se alegar que um sistema de confinamento para bovinos leiteiros no modelo compost barn se bem administrado, com um manejo adequado da cama, uma boa combinação da ventilação natural com a ventilação forçada (ventiladores) têm uma alta possibilidade de proporcionar bem-estar e conforto às vacas confinadas. Black et al. (2014) afirma que modelo de confinamento compost barn fornece um ambiente confortável às vacas, mas deve ser cuidadosamente gerenciado para garantir que a saúde do úbere não seja comprometida. Esses autores recomendam um controle da umidade, temperatura, relação $\mathrm{C}: \mathrm{N}$ da cama e o espaço por vaca na cama, para ajudar a reduzir algumas contagens de espécies bacterianas e a contagem de células somáticas.

Os bovinos leiteiros alojados em sistema de confinamento compost barn reduziu as lesões de claudicação e jarretes em comparação com àqueles alojados em sistemas de confinamento free stall (ROYÓN et al., 2013). Resultados semelhantes também foram encontrados em um estudo na região do Paraná, onde foi comparada a prevalência de claudicação e lesões nas pernas dos animais em lactação confinados em sistema free stall, compost -bedded packs, e uma combinação desses dois sistemas no Brasil (COSTA et al., 2018). Os autores verificaram uma menor prevalência de claudicação e lesões no jarrete e no joelho dos animais em fazendas usando apenas compost - bedded pack sem comparação com aqueles que usam apenas freestall ou as fazendas de freestall que usaram um compost -bedded packs estrategicamente para vacas vulneráveis. Relataram que apesar da previsão original do estudo não foi encontrado benefício fornecido pelo compost -bedded packs para vacas vulneráveis em conjunto com o uso free stall (COSTA et al., 2018).

\section{Conclusão}

Não foi verificado estresse térmico nos animais alojadas no confinamento no modelo compost barn na estação de verão e do inverno. Os parâmetros fisiológicos de temperatura retal, frequência respiratória e temperatura superficial da pele, se encontraram dentro dos limites de conforto animal. Existe um relacionamento maior entre a frequência respiratória (FR), temperatura superficial da pele (TS), temperatura retal (TR) e os índices de conforto animal no verão, quando comparada com o inverno. Para a análise dos escores de higiene e claudicação, com o passar dos meses, as vacas em lactação alojadas nesse sistema apresentaram uma melhoria na limpeza e um número muito baixo de vacas com problemas de cascos.

\section{Agradecimentos}

Os autores agradecem à Coordenação de Aperfeiçoamento de Pessoal de Ensino Superior (CAPES) por apoio financeiro.

\section{Referências}

ARAUJO, J. I. M. et al. Efeitos das variáveis climáticas sobre características fisiológicas de vacas mestiças (Holandês x Gir) em lactação. Revista Acadêmica: Ciência Animal, v. 14, p. 185-193, 2016.

AVILA, A. S. de. et al. Evaluation and correlation of physiological parameters and bioclimatic indexes holstein cows in different seasons. REGET, Santa Maria, v. 14, n. 14, p. 2878-2884, 2013. 
BANZATTO, D. A.; KRONKA, S. do N. Experimentação Agrícola, 4. ed. 5a Impressão. Jaboticabal, Funep, 2015. $237 \mathrm{p}$.

BERTONCELLI, P. et al. Conforto térmico alterando a produção leiteira. Enciclopédia Biosfera, Goiânia, v. 9, n. 17, p. 762-777, 2013.

BLACK, R. A. et al. Compost bedded pack dairy barn management, performance, and producer satisfaction. Journal of Dairy Science, v. 96, p. 8060-8074, 2013.

BLACK, R. A. et al. The relationship between compost bedded pack performance, management, and bacterial counts. Journal of Dairy Science, v. 97, p. 2669-2679. 2014.

BOND, G. B. et al. Métodos de diagnóstico e pontos críticos de bem-estar de bovinos leiteiros.Ciência Rural, Santa Maria, v. 42, n. 7, p. 1286-1293, jul. 2012.

COOK, N. B.; REINEMANN D. A tool box for assessing cow, udder and teat hygiene, In: 46th NATL. MASTITIS COUNC. MTG. PROC. San Antonio, Texas. Natl. Mastitis Council Inc., Madison, Wis., 2007. p. 31-43.

COSTA, J. H. C. et al. Prevalence of lameness and leg lesions of lactating dairy cows housed in southern Brazil: Effects of housing systems, Journal of Dairy Science, v. 101, n. 3, p. 1-12, 2018.

ECKELKAMP, E. A. et al. Sand bedded free stall and compost bedded pack effects on cow hygiene, locomotion, and mastitis indicators, Livestock Science, v. 190, p. 48-57, 2016.

FERREIRA, D. F. Estatística básica. 1. ed. Lavras: Ed. Ufla, 2005. $664 \mathrm{p}$.

FERREIRA, D. F. 2011. Sisvar: A computer statistical analysis system. Ciência e Agrotecnologia. Lavras, v. 35, n. 6, p. 1039-1042.

FERREIRA, R. A. Maior Produção com Melhor Ambiente: Para Aves, Suínos e Bovinos. Viçosa, MG, 3. ed. Aprenda Fácil, 2015. 526 p.

LESO, L. et al. Evaluating thermal performance of experimental building solutions designed for livestock housing: the effect of greenery systems Agronomy Research, v. 15, n. 1, p. 239-248, 2017.

KAWABATA, C. Y.; CASTRO, R. C. DE; JÚNIOR, H. $\mathrm{S}$. Índices de conforto térmico e respostas fisiológicas de bezerros da raça holandesa em bezerreiros individuais com diferentes coberturas, Engenharia Agrícola, Jaboticabal, v. 25, n. 3, p. 598-607. 2005.

MOTA, V. C. CAMPOS, A. T.; DAMASCENO, F. A.; RESENDE, E. A. DE M.; REZENDE, C. P. DO A., ABREU, L. R. DE; VAREIRO, T. Confinamento para bovinos leiteiros: Histórico e características. PUBVET, v.
11, p. 433-442. 2017.

MOTA, V. C. Modelagem fuzzy, geoestatística e estatística na avaliação de sistema de confinamento para bovinos no modelo Compost Barn, 2018, Tese (Doutorado em Engenharia Agrícola) - Universidade Federal de Lavras - UFLA, Lavras, 2018.

MOTA, V. C.; DAMASCENO, F. A.; LEITE, D. F. Fuzzy clustering and fuzzy validity measures for knowledge discovery and decision making in agricultural engineering. Computers and Electronics in Agriculture, Amsterdã Holanda, v. 150, p. 118-124. 2018.

MOTA, V. C.; ANDRADE, E. T. de; LEITE, D. F. Bed temperature in compost barns turned with rotary hoe and offset disc harrow. Engenharia Agrícola. Jaboticabal - SP, v. 39, n. 3 , p. $280-287,2019$.

MOTA, V. C.; ANDRADE, E. T. de; PINTO, S. M.; ABREU, L. R. de; LEITE, D. F. Utilization of bedded cattle confinement for organic manure of maize crop. Revista Brasileira de Engenharia Agrícola e Ambiental, Campina Grande - PB, v. 23, n. 8, p. 620-624, 2019.

MOURA, A. K. et al. Influências bioclimáticas e de ambiência no bem-estar de vacas leiteiras. PUBVET, Londrina, v. 4, n. 32, ed. 137, Art. 926. 2010.

PILATTI, J. A.; VIEIRA, F. M. C. Environment, behavior and welfare aspects of dairy cows reared in compost bedded pack barns system. Journal Animal Behaviour Biometeorology, v. 5, p. 97-105. 2017.

PINHEIRO, A. da C. et al. Características anatomofisiológicas de adaptação de bovinos leiteiros ao ambiente tropical. Agropecuária Técnica, v. 36, n. 1, p. 280-293, 2015.

SILVA, S. Comportamento e bem - estar de animais: a importância do manejo adequado para os animais de produção. Viçosa, MG: Aprenda Fácil, 2016. 310 p.

SOUZA, P. T. de; SALLES, M. G. F.; ARAUJO, A. A. de. Impacto do estresse térmico sobre a fisiologia, reprodução e produção de caprinos. Ciência Rural, Santa Maria, v. 42, n. 10 , p. $1888-1895$, out. 2012

ROYÓN, F. D.; ENDRES, M. I.; GARCÍA, Á. D. CrossVentilated Barns for Dairy Cows: New Building Design with Cow Comfort in Mind. eXtension, p. 1-14, 2013. Disponível em: http://articles.extension.org:80/pages/68439/ cross-ventilated-barns-for-dairy-cows:-new-buildingdesign-with-cow-comfort-in-mind). Acesso em: 20 maio 2018 .

SOMERS, J. R. et al. The effect of Lameness before and during the breeding season on fertility in 10 pasture-based Irish dairy herds. Irish Veterinary Journal, v. 68, n. 14, p. 1-7. 2015

SPRECHER, D. J.; HOSTETLER, D. E.; KANEENE, 
J. B. A lameness scoring system that uses posture and gait to predict dairy cattle reproductive performance. Theriogenology, v. 47, n. 6, p. 1179-1187. 1997.

ZERO, R. C.; MELLO S. de P. Fatores ambientais na resposta fisiológica e comportamental de vacas leiteiras, Nucleus Animalium, v. 7, n. 2, 2015.

Recebido em: 28.08.2018

Aceito em: 18.09.2020 